pensable, and that the results obtained by the use of
chemical fertilizers will be in direct proportion to the amount of organic matter with which these fertilizers have been associated.-L'Engrais.

SEPARATION OF OXYGEN FROM THE ATMOSPHERE.

By H. N. WARREN.

THE diffusion or osmotic properties of a gas, when compared with another of opposed density, have been
pointed out from an early date, perhaps one of the simplest means of observing the same being the swift passage of hydrogen gas when in admixture with one brane. So perfect, however, is this peculiar separation
in the case of hydrogen when in admixture with an equal bulk of oxygen, the operation being performed in a caoutchouc bag kept weighted, that on examining the will be observed to have escaped, so as to totally destroy the explosive nature of the mixture.

stroy the explosive nature of the mixture. to condense gases upon its surface, an apparatus has or partial separation of oxygen gas from the atmois composed of two somewhat powerfully exhausting is composed of two somewhat powerfully exhausting
syringes, A and B, the top extremity of each being
provided with a cock, and connected to the same two small gas bags, the bottom or further extremity of each syringe being connected with a porous pot, D,
provided internally with two disks of compressed charcoal, and charged with a preparation of finely divided using, in a solution of caoutchouc in naphtha. The outer wall of the porous cylinder is also provided with $\mathrm{E}$, in connection with the cork, $\mathrm{C}$, being pierced with two small orifices, and terminating at the commence-
ment of the second disk, and intended to remove the nitrogenous atmosphere remaining in the cylinder after the separation of the oxygen by means of the
syringe, A. The piston rod of the syringe, A, being now the porous eylinder, $D$, and being surrounded by the atmosphere, an inward pressure is at once experienced, an atmosphere extrenely rich in oxygen, and also wit

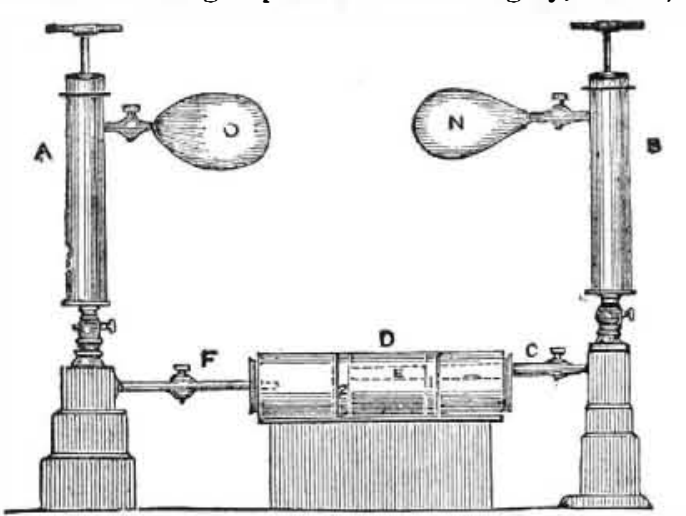

working thepistonon eitherside of the cylinderwith due $\mathrm{O}$ and $\mathbf{N}$, intended for the reception of the same. On submitting both portions of these separated gases to A, was found to be sufficiently rich in oxygen to readily A, was found to be sufficiently rich in oxygen to readily rekinale a glowing splint, and even support the com-
bustion of iron wire, results of several analyses prov-
ing an existence of 50 per cent. of oxygen, while the ing an existence of 50 per cent. of oxygen, while the
nitrogenous atmosphere collected by the opposite cyl-
inder readily extinguished a lighted match when ininder readily extinguished a lighted match when in arrangement of the apparatus a mixture of hydrogen and oxygen was separated so effectively as to produce made to ignite. Carbonic anhydride and variou other gases in admixture with one another were ex
mented upon with a like result.--Chemical News.

\section{NICKEL AND COBALT.}

DR. KRUSS, of Munich, has recently reported that, nickel and cobalt, he has been able to demonstrate that neither of these bodies are elementary substances.
The atomic weights of nickel and cobalt are, as is well known, almost identical, and Dr. Kruss considered that a redetermination of these contants might throw
some iight on the very close relationship which exists between these two bodies. Dr. Kruss has been engaged on a long and laborious investigation on the atomic weight of gold, and the importart work which he has
published on this subject has shown that his careful methods of procedure, and accurate work, could not be
better employed than in an investigation such as the better employed than in an investigation such as the
one he has undertaken. The method suggested by Winkler for attacking this
ond problem is based on the decomposition of gold chloride by nickel and cobalt, and thus the previous work of Dr.
Kruss rendered him particulirly suited for undertak-
ing the investigation. He found that the gold sepaing the investigation. He found that the gold sepa-
rated in the reaction contained some substance which gave a green color in acid solutions, and a white pre-
cipitate on the addition of alkalies. By fusing oxide mass with water, Dr. Kruss has obtained a solution which contained some of this hitherto unknown material, while the pure oxide of nickel or cobalt remains undissolved. The oxide of the common element pre-
sent in nickel and cobalt oxides is of a white color, and readily soluble in hydrochloric acid. It can be reduc-
ed by charcoal to a brown metallic powder, and anbrown sulphide. It also appears that a small quantity of the chloride of this substance added to a solution of
cobalt chloride changes its color from red to green, and the author is therefore of opinion that what has hitherto been considered nickel in solution is a mixture
of the salts of cobalt and this new element. The quan-

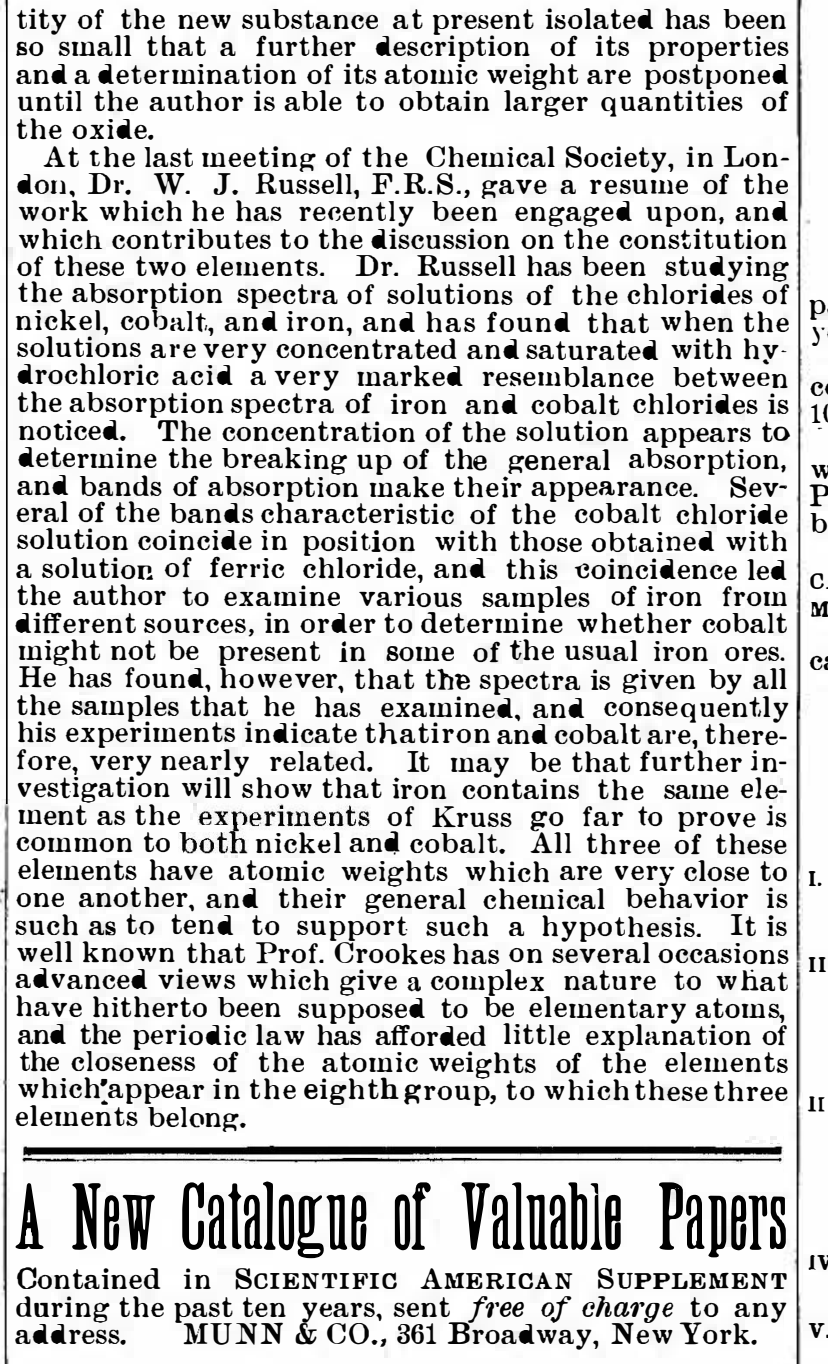

\section{THE SCIENTIFIC AMERICAN} Architects ain Builders Edition.

$\$ 2.50$ a Year. Single Copies, 25 cts.

This is a Special Edition of the ScIENTIFIC AMERIAN, issued monthly-on the first day of the month equal to about two hundred ordinary book pages forming, practically, a large and splendid Magazine in colors and with fine engravings, illustrating the most interesting examples of

A special feature is the presentation in each number

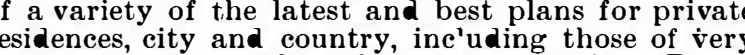
noderate cost as well as the more expensive. Draw
ngs in perspective and in color are given, together
with full Plans, Specifications, Costs, Bills of Estimate, No other building paper contains so many plans
No No other building paper contains so many plans,
Sctails, and specifications regularly presented as the
ScIENTIFIC AMERICAN. Hundreds of $d$ wellings have already been erected on the various plans we have Architects, Builders, and Owners will find this work valuable in furnishing fresh and useful suggestions.
All who contemplate building or improving homes, erecting structures of any kind, have before them in
this work an almost endless series of the latest and be examples from which to make selections, thus saving
time and money. Many other subjects, including Sewerage, Piping out of Grounds, etc., are illustrated. An extensive approved Buildg Materials, Goods, Machines, Tools, and Appliance re described and illustrated, with addresses of the
The fullness, richness, cheapness, and convenience of
The etcen this work have won for it the Largest Circulation of any Architectural publication in the world. Building, Carpentry, Masonry, Heating, Warming, Lighting, Ventilation, and all branches of industry
pertaining to the art of Building, is supplied free of charge, sent to any address.

Publishers, 361 Broadway, New York.

Building Plans and Specifications.

In connection with the publication of the BuILdive EDITION of the ScIENTIFIC AMERICAN, Messrs. Munn
\& Co. furnish plans and specifications for buildings of every kind, including Churrehes, Schools, Stores,
Dwellings, Carriage Houses, Barns. etc. In this work they are assisted by able and experiiod architects. Full plans, details, and specifica-
ions fcr the various buildings illustrated in this paper Those who contemplate building, or who wish to
the alter, improve, extend, or add to existing buildings,
whether wings, porches, bay windows, or attic rooms, Our work extends to all parts of the country. Estimoderate. Address MUNN \& CO., 361 BROADWAY, NEW YORK.
TII

\section{Scientific American Supplement.} PUBLISHED WEEKLY.

Terms of Subscription, $\$ 5$ a year.

Sent by mail, postage prepaid, to subseribers in any
part of the United States or Canada. Six dollars a ear, sent, prepaid, to any foreign country. All the back numbers of THE Su PPLEMENT, from the
amment, January 1,1876 , can be had. Price. 10 cents each.
All the back volumes of THE SUPPLEMENT can likeAll the back volumes of THE SuPPLEMENT can like
wise be supplied. Two volumes are issued yearly.
Price of each volume, $\$ 2.50$ stitched in paper, or $\$ 3.50$ bound in stiff covers. COMBINED RATES.-One copy of ScIENTIFIC AMERICAN and one copy of SCIENTIFIC AMERICAN SUPPLE-
MENT, one year, postpaid, $\$ 7.00$.
A liberal discount to booksellers, news agents, and A liberal discount to booksellers, news ag
canvassers.
MUNN \& CO., Publishers, 361 Broadway, New York, N. Y.

TABLE OF CUNTENTS. AGRICULTURE.-The Loss of Nitrogen Caused by Working and
Aerating the soil-A A very curious and interesting point in apri-
culture investigated.- - The results of cultivation without enrich-

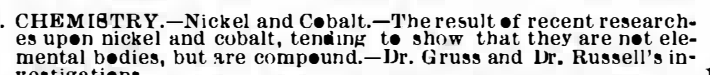

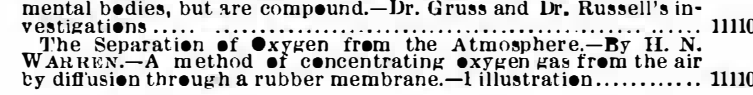

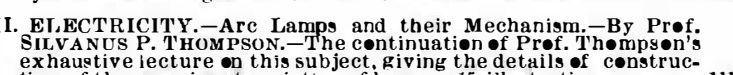

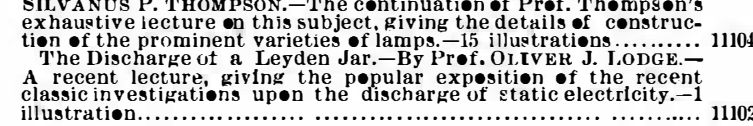

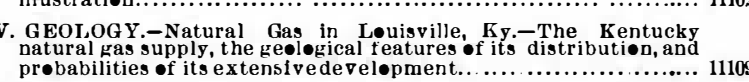

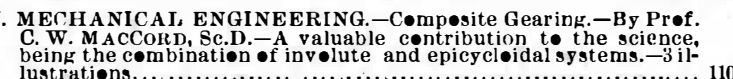

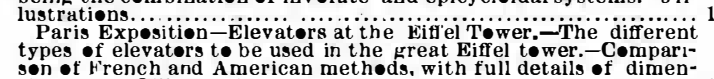

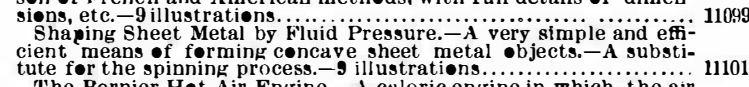

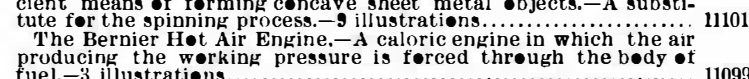

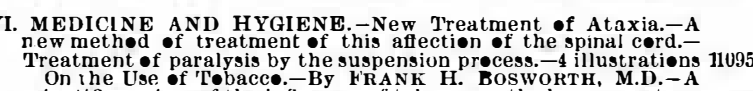

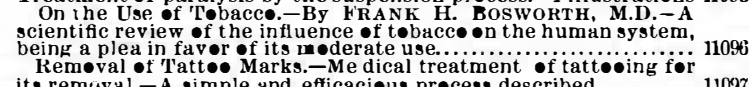

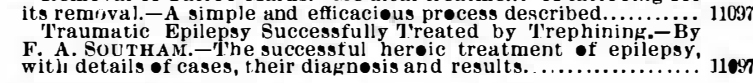

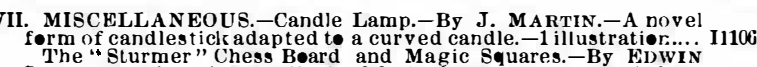

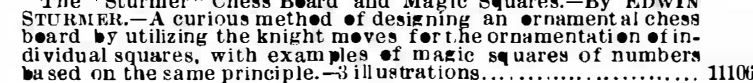

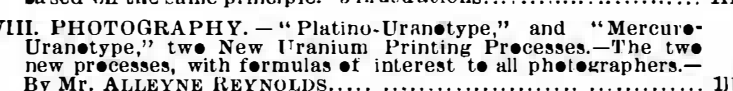

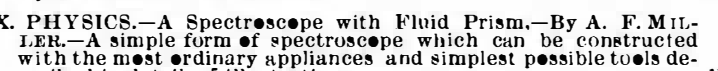

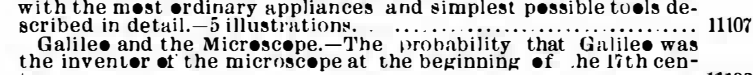

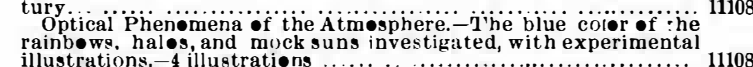

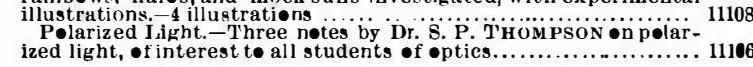
THECHNOLOGY-S Sulphuric A Aid. - A review of the American sul- 1101
phuric acid industry as well as of its development in Europe.......

\section{Useful Engineering Books} Manufacturers, Agriculturists, Chemists, Engineers,
Mechanies, Builders, men of leisure, and professional
men, of all classes, need good books in the line of their men, of all classes, need good books in the line of their
respective callings. Our post office department permits small cost. A comprehensive catalogue of useful books ects, has recently been published, for free circulation, to ask for it, and it will be mailed to them. Address, MUNN \& CO., 361 Broadway, New York.

\section{PATENTS.}

In connection with the Scientific American,
Messrs. MUNN \& Co. are solicitors of American and Foreign Patents, have had 42 years' experience, and
now have the largest establishment in the world. Patents are obtained on the best terms.
A special notice is made in the Scientific American of all inventions patented through this Agency,
with the name and residence of the Patentee. By the mmense circulation thus given, public attention is introduction of ten easily effected. Any person who has made a new discovery or inven-
tion can ascertain, free of charge. whether a patent can probably be obtained, by writing to MuNN \& Co.
We also send free our Hand Book about the Patent We also send free our Hand Book about the Patent
Laws, Patents, Caveats, Trade Marks, their costs and

\section{MUTIII de OO.} 361 Broadway, New York. Braneh Omee, 622 and 624 F St., Washington, D. C. 